\title{
Improving Interaction Competencies With Children-A Pilot Feasibility Study to Reduce School Corporal Punishment
}

\author{
Elisa Kaltenbach ${ }^{\mathrm{a}}$, Katharin Hermenau ${ }^{\mathrm{a}, \mathrm{d}}$, Mabula Nkuba ${ }^{\mathrm{a}, \mathrm{b}}$, Katharina Goessmann ${ }^{\mathrm{a}}$, \\ and Tobias Hecker $\mathbb{P}^{\text {c,d }}$ \\ aDepartment of Psychology, University of Konstanz, Konstanz, Germany; 'bepartment of Psychology \\ and Curriculum Studies, Dar es Salaam University College of Education, Dar es Salaam, Tanzania;

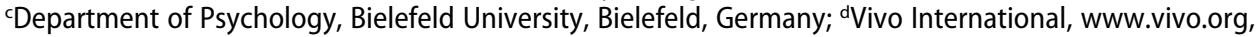 \\ Konstanz, Germany
}

\begin{abstract}
High prevalence rates of corporal punishment in schools worldwide and the associated negative mental health issues show the need for interventions addressing this problem. Yet, so far there are very few intervention studies aimed at altering corporal punishment administered by teachers, particularly in low- or middle-income countries.

To conduct a feasibility study of the newly developed intervention approach, Interaction Competencies with Children for Teachers (ICC-T) - a training workshop designed to prevent corporal punishment and improve the teacher-student relationship. The 1-week ICC-T intervention was conducted with 30 teachers in a Tanzanian primary school. Participants filled out a survey before, directly after, and 3 months following the intervention. The widespread use of corporal punishment indicated strong demand for a preventive intervention. The feasibility of ICC-T was good: Despite challenging conditions, implementation of the training and participants' acceptance was high. Further, participants reported a good integration of the training's core elements in their daily working routine, improvements in the teacher-student relationships, and in the students' behavior. ICC-T shows a promising feasibility in the Tanzanian teacher sample. These encouraging results highlight the need for further studies testing the efficacy, sustainability, and effects of ICC-T on the students' well-being.
\end{abstract}

\section{Introduction}

\section{Corporal punishment in schools: A global phenomenon}

To date, corporal punishment remains legal in many schools worldwide (Gershoff, 2017; Global Initiative to End All Corporal Punishment of Children [GIEACPC], 2015b). It is still not fully prohibited in schools 
in 70 of the 198 countries tracked in a recent report from the GIEACPC (2016d). The deficient legislation in relation to corporal punishment suggests that it is still a widespread phenomenon in schools worldwide; however, representative prevalence rates of corporal punishment are difficult to assess, particularly in low-income countries (Devries et al., 2014). Nevertheless, research on this topic is growing, and current findings indicate the frequent use of violent discipline in schools in low- and lower-middle-income countries (LIC and LMIC) around the globe, particularly in African and Asian countries (GIEACPC, 2015a). For the majority of the LIC and LMIC studied, high prevalence rates of over $50 \%$ were reported (Antonowicz, 2010; Feinstein \& Mwahombela, 2010; Gershoff, 2017; GIEACPC, 2016b; Portela \& Pells, 2015). Even in countries where school corporal punishment is legally prohibited, its ongoing use remains high (Gershoff, 2017).

\section{School corporal punishment in Sub-Saharan Africa}

A large number of children in Sub-Saharan Africa (SSA) are at particularly high risk of experiencing corporal punishment in school-25 of the 70 countries not fully prohibiting corporal punishment in schools are located in this area (GIEACPC, 2016d). Research from schools in 13 different SSA countries revealed rates of children reporting corporal punishment ranging from $11 \%$ to $95 \%$, and the witnessing of corporal punishment ranging from 34\% to 98\% (Burton, 2005; Devries et al., 2014; GIEACPC, 2016b; Hecker, Hermenau, Isele, \& Elbert, 2014). A study in the Central African Republic reported that $52 \%$ of primary school teachers inflict corporal punishment on a daily basis (Antonowicz, 2010). Corporal punishment in schools in SSA is regularly applied even for minor offenses, such as tardiness or answering a question incorrectly, and leads to feelings of humiliation in children (Anbarasan, 1999; Naker, 2005).

The frustrating and stressful working conditions of teachers in LIC contribute to the excessive use of corporal punishment (Feinstein \& Mwahombela, 2010; Greydanus et al., 2003; Mweru, 2010). Teachers in LIC and LMIC are constantly challenged to cope with the absence of basic resources like insufficient school equipment, lack of personnel, and deficient school management. This results in overcrowded classrooms, limited teaching and learning resources, and hierarchical authority structures (Barrett, 2005; Bennell \& Akyeampong, 2007; Vavrus \& Bartlett, 2012). Bennell and Akyeampong (2007) reported that more than three quarters of the teachers in five SSA countries indicated their working conditions to be poor, demotivating, and stressful. Not surprisingly in this context, maltreatment has been reported to be more prevalent in educational settings shaped by high stress and limited resources (Benbenishty, Zeira, \& Astor, 2002; Khoury-Kassabri, 2006). 


\section{Current situation in Tanzania}

Consistent with many other SSA countries, in Tanzania corporal punishment is legal, though the country is a signatory to the Convention on the Rights of the Child (GIEACPC, 2015a, 2016c). Despite government guidelines limiting corporal punishment in Tanzanian schools to four strokes administered by head teachers only (GIEACPC, 2016c), the use of corporal punishment by regular teachers is supported by authorities (Tanzania Daily News, 2013). Further, teachers' regular training does not equip them to handle children's misbehavior in nonviolent ways (Nkuba \& Kyaruzi, 2015). Therefore, it is not surprising that there is a high and recurring use of corporal punishment by regular teachers (Feinstein \& Mwahombela, 2010; Frankenberg, Holmqvist, \& Rubenson, 2010; Research and Analysis Working Group United Republic of Tanzania, 2007; Yaghambe \& Tshabangu, 2013). In a recent study by Hecker et al. (2014) almost all students at a primary school in Tanzania reported experiencing corporal punishment at school.

\section{Consequences of corporal punishment}

Research on consequences of corporal punishment shows that it carries multiple risks of harm and has no long-term benefits (Gershoff, 2002; Norman et al., 2012). Meta-analyses and comprehensive studies have consistently found negative effects of corporal punishment on children's physical and psychological state, especially associations with depressive disorders, suicide attempts, aggression, antisocial behavior, and substance abuse (Gershoff, 2002; Gershoff \& Grogan-Kaylor, 2016; Hecker et al., 2014; Hyland, Alkhalaf, \& Whalley, 2013; Naker, 2005; Norman et al., 2012; World Health Organization, 2002). Further, corporal punishment was associated with poorer academic performance (Antonowicz, 2010; Boden, Horwood, \& Fergusson, 2007; Tomoda et al., 2009), as well as with negative consequences later on in the children's life, for example, delinquent behavior and victimization of ongoing physical abuse (Gershoff, 2002; McCabe, Lucchini, Hough, Yeh, \& Hazen, 2005; Pereznieto, Harper, Clench, \& Coarasa, 2010).

In the context of school corporal punishment, a recent review of Gershoff (2017) found comparable negative effects. In addition to the general negative consequences, corporal punishment in school increased children's fear of going to school, created a violent and humiliating learning environment, eroded the students' trust in schools and teachers, and led to increased levels of school drop-out (Antonowicz, 2010; Gershoff, 2017). It further interfered with the children's cognitive abilities, with lasting negative impacts on students' verbal and executive functioning (Antonowicz, 2010; Portela \& 
Pells, 2015; United Nations Children's Fund, 2014). Thereby it contradicted the intended outcome of improving discipline and school performance (Gershoff, 2017; GIEACPC, 2016a; Hecker, Hermenau, Salmen, Teicher, \& Elbert, 2016). The depicted consequences also lead to negative long-term effects at the societal level, such as lower income and higher use of social and health services (Gershoff, 2017; Pereznieto et al., 2010). Hence, the United Nation's Sustainable Development Goal Nr. 16.2 (United Nations, 2015) is to end all forms of violence against children in order to address this global public health challenge.

\section{Interventions targeting corporal punishment in school settings}

General recommendations to stop school corporal punishment include a legislative reform banning corporal punishment, education about the negative consequences of corporal punishment, provision of alternative discipline methods, and possibilities for reporting the use of corporal punishment and appropriate penalties (Gershoff, 2017; GIEACPC, 2016b). Further, there are several in-depth resources for teachers, such as guide books, toolkits, or websites addressing this topic (GIEACPC, 2012). However, only a few interventions aimed at altering violent disciplinary styles by school teachers have been conducted (Global Advocacy Team, 2012; Parkes \& Heslop, 2013), and even fewer have been scientifically evaluated (Bonell et al., 2013). Devries et al. (2015) recently conducted a methodically comprehensive cluster-randomized controlled study, training teachers in nonviolent disciplinary methods. It aimed at changing behavior in school staff and students in 42 primary schools in Uganda by providing training sessions and school-wide support in terms of knowledge on alternative non-violent discipline, reflection, skill practice, and ongoing supervision. Their intervention reduced corporal punishment by $42 \%$ (Devries et al., 2015). There have also been a few other studies performing interventions with school staff and/or students; however, they did not deal with corporal punishment, but instead mainly focused on changing students' misbehavior (Flannery et al., 2003; Nolan, Filter, \& Houlihan, 2014; Schiff \& BarGil, 2004) or on reducing teachers' stress (Flook, Goldberg, Pinger, Bonus, \& Davidson, 2013; Schussler, Jennings, Sharp, \& Frank, 2016; Taylor et al., 2016).

\section{Objectives}

At the present time, there have not been any scientifically evaluated interventions to prevent corporal punishment in Tanzanian schools. The lack of interventions, especially in regions with high prevalence rates of school corporal punishment and limited resources for prevention, highlights the urgent need to develop comprehensive intervention approaches to support 
teachers in changing their attitudes towards corporal punishment and provide them with nonviolent action alternatives. This is all the more significant as corporal punishment in schools is an important but often overlooked contributor to the public health burden associated with child physical abuse (Devries et al., 2015).

To bridge this gap, the intervention approach, Interaction Competencies with Children for Teachers (ICC-T), was designed. Given the shortage of research in this area, conducting a pilot feasibility study that assessed the demand, acceptability, implementation, integration, and limited effectiveness of ICC-T was indicated.

\section{Method}

\section{Participants}

The feasibility study was conducted with 30 teachers of one English medium primary school (i.e., English is the language of educational instruction) in southern Tanzania. The students in the primary school had already participated in a cross-sectional study on the consequences of corporal punishment on mental health and school performance (Hecker et al., 2014, 2016). All teachers in this school were invited to participate. Of these, $83 \%(n=30$ of 36) participated. No exclusion criteria were applied. The participants were on average 34.93 years old $(S D=11.92$; range $23-71 ; n=30)$ and $55 \%(n=16$ of $29)$ were female. They reported on average 14.92 years of formal education $(S D=2.12$; range $11-22 ; n=26)$. The participants taught classes from the first to 7 th year of formal schooling, with students between six and 15 years of age. Class size was around 50 students per class.

\section{Design and procedure}

The study took place in the facilities of the cooperating primary school. First, the teachers participated in a baseline survey assessing the demand for training. Subsequently, they attended the ICC-T training workshop. A total of 73\% $(n=$ 22 of 30 ) participated in the entire training (defined as attending more than $80 \%$ of the training sessions). Further data from the teachers was collected, both directly after the training workshop and 3 months afterwards. Drop-out at the 3months follow-up was $23 \%$ ( $n=7$ of 30 ). Additionally, trainers evaluated the implementation of each ICC-T session and notes were taken during the training workshop (for more details see Figure 1).

One Tanzanian and one German psychologist conducted the ICC-T training workshop, with the help of three assistant facilitators. The training workshop was held during school holidays and conducted in English. The management of the school invited all teachers to take part in the training workshop. The 


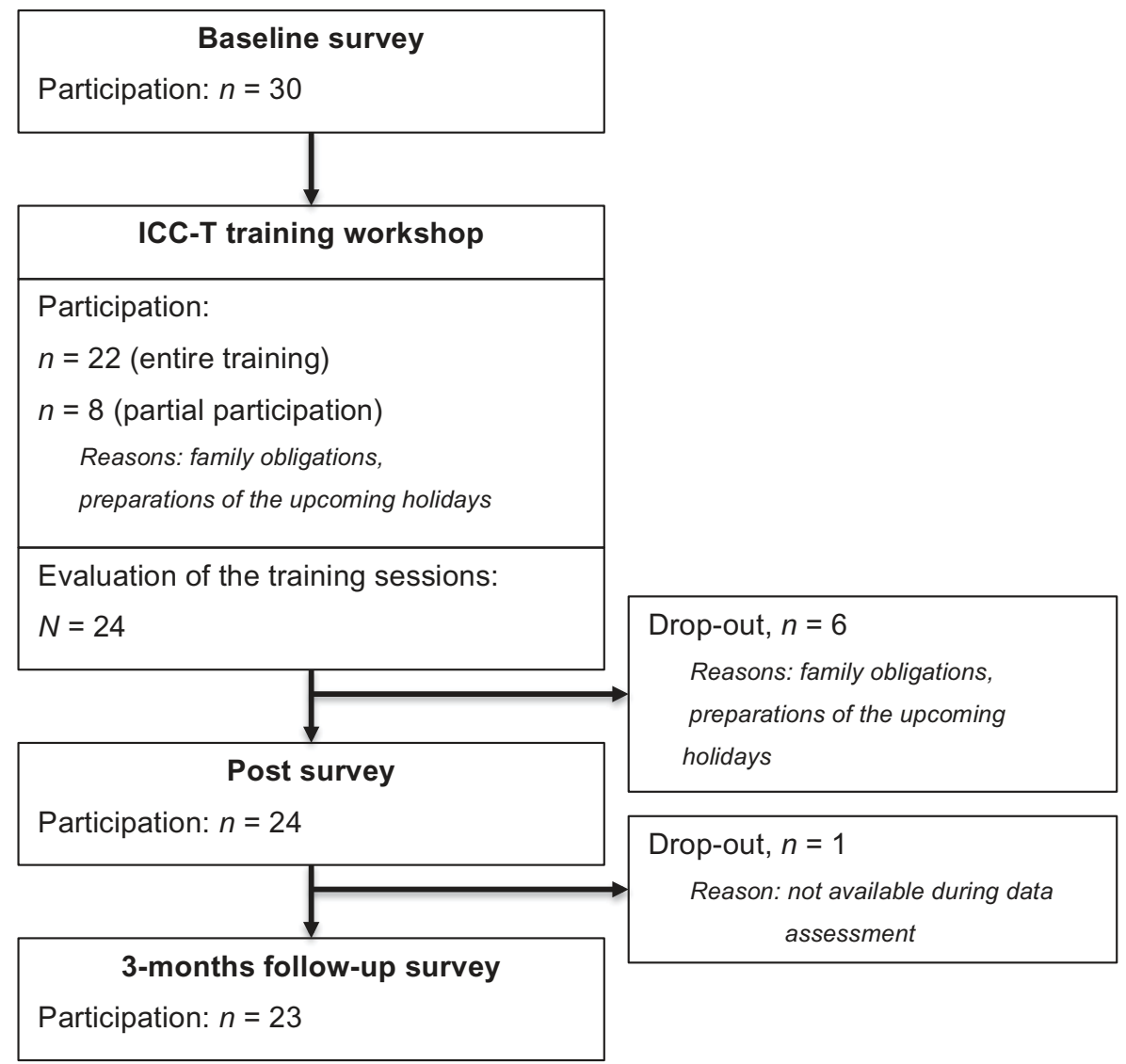

Figure 1. Flow-chart of the study design.

workshop was free of charge for the teachers and without financial compensation; however, they received free beverages and food. The study has been conducted according to the principles expressed in the Declaration of Helsinki. Informed consent was obtained from all participants at the beginning of the study. Teachers' participation in the study's assessments and training workshop was voluntary and independent from each other. Participants were informed that they were free to end their participation at any time without consequences. Furthermore, all participants agreed that the information and quotations gathered in the assessments and during the intervention could be published for scientific purposes in anonymized form. They were assured that all personal information would be kept strictly confidential.

\section{Intervention}

The intervention was a 5.5 day ( 8 hours on a full day) training workshop for teachers. The preventive intervention approach, Interaction Competencies with Children (ICC), aims at preventing maltreatment and 
improving the adult-child relationship by introducing essential interaction competencies in the work with children. The training concept follows the childcare guidelines of The American Academy of Pediatrics (1999) and is available for different target groups. A good feasibility and first evidence for its effectiveness has already been found for caregivers working in institutional care settings (Hermenau, Kaltenbach, Mkinga, \& Hecker, 2015). The present study tested the feasibility of ICC-T. The specific focus of ICC-T is on preventing corporal punishment as a disciplinary measure in school settings and on improving the teacher-student relationship. Key principles of ICC-T are:

(a) Participative approach: Participants are encouraged to participate actively and to strategize how to implement ICC-T components in their daily work.

(b) Practice: Theory and practice are combined to enable participants to use the acquired ICC-T skills in everyday school life.

(c) Trustful atmosphere: Confidentiality is assured and participants are invited to talk openly about work problems, their needs, and experiences with corporal punishment to create a trusting and open atmosphere.

(d) Sustainability: Intensive practicing, reinforcement and repetition of the content, self-reflection about own behavior, team building measures, and organization of a peer consulting system are emphasized to ensure sustainability of the ICC-T training workshop.

Five core components form the ICC-T training, with the aim of establishing a better relationship between teachers and students and to decrease corporal punishment. This is predicted to ultimately improve the children's well-being. For more detailed information on the ICC-T content see Table 1.

(1) The sessions about teacher-student interaction aimed to foster empathy and understanding of the students' behavior, raise awareness of the responsibility of being a role model for the students, create a good learning atmosphere, and improve teacher-student interactions.

(2) The sessions on maltreatment prevention aimed to raise awareness of the negative consequences of corporal punishment for the children's well-being. Teachers reflected on their own experiences of corporal punishment as a child and on their use of corporal punishment as a teacher, with the aim of connecting their own experiences and feelings to their current behavior and its consequences. These sessions were closely linked to the sessions about effective discipline strategies 
Table 1. Overview of Interaction Competencies With Children-Teacher Version (ICC-T).

\begin{tabular}{|c|c|}
\hline Component & Content $^{\mathrm{a}}$ \\
\hline Teacher-student interaction & $\begin{array}{l}\text { - Communication skills } \\
\text { - Instructions and expectations } \\
\text { - Teachers as role models and its implications } \\
\text { - Structure, rituals, and rules in the classroom }\end{array}$ \\
\hline Maltreatment prevention & $\begin{array}{l}\text { - Discussion about common discipline strategies in the relevant } \\
\text { country } \\
\text { - Consequences of corporal punishment } \\
\text { - Self-reflection about own experiences of corporal punishment as a } \\
\text { child } \\
\text { - Self-reflection about own experiences when using corporal } \\
\text { punishment } \\
\text { - Myths about the effectiveness of corporal punishment } \\
\text { - Practice of alternative strategies to corporal punishment (connected } \\
\text { with component effective discipline strategies) }\end{array}$ \\
\hline Effective discipline strategies & $\begin{array}{l}\text { - Introduction of non-violent strategies to maintain good behavior } \\
\text { (e.g., reinforcement systems, contracts, etc.) } \\
\text { - Introduction of strategies to change misbehavior (e.g., time-out, pri- } \\
\text { vilege removal, etc.) } \\
\text { - Practice of introduced strategies in role plays }\end{array}$ \\
\hline $\begin{array}{l}\text { Identifying and supporting } \\
\text { burdened students }\end{array}$ & $\begin{array}{l}\text { - Stress in children } \\
\text { - Delayed development } \\
\text { - Externalizing problems: Aggressive and oppositional behavior } \\
\text { - Internalizing problems: Depression and social withdrawal } \\
\text { - Discussion about specific cases } \\
\text { - Elaboration of strategies to support burdened children }\end{array}$ \\
\hline Implementation & $\begin{array}{l}\text { - Implementation of the new knowledge into everyday school life } \\
\text { - Collaboration with other teachers and the school counselor } \\
\text { - Organization of a peer consulting system }\end{array}$ \\
\hline
\end{tabular}

${ }^{a}$ The components included presentations by the trainers, discussions (in the plenary and in small groups), record of the results, role plays, and repetitions.

aiming to reduce the teachers' use of corporal punishment and other forms of emotional and physical maltreatment.

(3) The introduction and practice of different effective discipline strategies aimed to provide the teachers with tools on how to maintain and reinforce desired behavior, and how to change or improve undesirable behavior. The aim is to reduce misbehavior by giving non-violent alternatives to corporal punishment and reducing feelings of helplessness.

(4) Identifying and supporting burdened students aimed to raise awareness for common emotional and behavioral problems and to show how to identify and support them in the school context.

(5) The sessions on implementation aimed at ensuring the realization of the ICC-T components in everyday school life and were essential for the sustainability and efficacy of the ICC-T approach. Furthermore, establishing support strategies to improve the working atmosphere for teachers were implemented, including a peer consulting system and the collaboration with school-counselors and parents. 


\section{Measures}

The baseline survey and the two surveys following the training were conducted as self-administered questionnaires in English. The baseline survey took 30 minutes; the other two surveys took 20 minutes each. Due to the lack of established and validated assessment tools in this research area, most questions were purpose-built. All three surveys included quantitative and qualitative questions.

The present study applied the guidelines for feasibility studies of Bowen et al. (2009). Accordingly, the demand, implementation, acceptability, integration, and limited effectiveness of ICC-T were assessed. The baseline survey assessed the demand for training by measuring the working conditions of the teachers (e.g., working hours, difficulties at work, workload). The work-related burnout section of the Copenhagen Burnout Inventory (CBI; Kristensen, Borritz, Villadsen, \& Christensen, 2005), which showed a good reliability and validity in a teacher sample (Milfont, Denny, Ameratunga, Robinson, \& Merry, 2008), assessed stress at work. CBI items, measured on a 5 -point Likert scale, are added to a sum score ranging from 0 to 100, with high burnout being defined as $\geq 50$ (Borritz, Rugulies, Christensen, Villadsen, $\&$ Kristensen, 2006). Additionally, qualitative data about the attitude and use of corporal punishment was assessed through transcription during the training, especially during the sessions about maltreatment prevention. In this part, the number of participants answering the questions varies, depending on how many participants narrated something on the relevant topics. Acceptability and implementation of the training was measured in the survey directly after ICC-T training. Further, the trainers evaluated the implementation of each ICC-T session throughout the training (see Supplementary Table 1). Integration into daily life and limited effectiveness were assessed through the teacher's report 3 months after the training. For more information on the content of the questions see Supplementary Table 2.

\section{Data analysis}

Qualitative data was analyzed using inductive content comparison analysis (Leech \& Onwuegbuzie, 2007): The collected data was read and two independent raters clustered the data into smaller content-related parts. These were then labeled with descriptive titles and sorted by similarity thereby identifying themes. Differences between the two raters were discussed intensively. Additionally, classical content analysis was used to assess the number of participants who reported each theme (Leech \& Onwuegbuzie, 2007). As multiple responses were possible, total percentage scores were higher than $100 \%$. Examples are presented throughout the study. Quantitative data was reported descriptively using SPSS version 21 . 
Table 2. Results of the Work-Related Burnout Section of the Copenhagen Burnout Inventory.

\begin{tabular}{|c|c|c|c|c|c|c|}
\hline Question & $M(S D)$ & $\begin{array}{c}0 \\
\%(n) \\
\end{array}$ & $\begin{array}{c}25 \\
\%(n) \\
\end{array}$ & $\begin{array}{c}50 \\
\%(n)\end{array}$ & $\begin{array}{c}75 \\
\%(n) \\
\end{array}$ & $\begin{array}{c}100 \\
\%(n)\end{array}$ \\
\hline 1. Is your work emotionally exhausting? & $45.54(27.26)$ & $17.9(5)$ & $14.3(4)$ & $35.7(10)$ & $32.1(9)$ & $0(0)$ \\
\hline 2. Does your work frustrate you? & $32.41(26.69)$ & $29.6(8)$ & $25.9(7)$ & $29.6(8)$ & $15.8(4)$ & $0(0)$ \\
\hline $\begin{array}{l}\text { 3. Do you feel burnt out because of your } \\
\text { work? }\end{array}$ & $30.36(25.78)$ & $32.1(9)$ & $25.0(7)$ & $32.1(9)$ & $10.7(3)$ & $0(0)$ \\
\hline $\begin{array}{l}\text { 4. Do you feel worn out at the end of the } \\
\text { working day? }\end{array}$ & $50.00(21.52)$ & $7.1(2)$ & $7.1(2)$ & $71.4(20)$ & $7.1(2)$ & $7.1(2)$ \\
\hline $\begin{array}{l}\text { 5. Do you have enough energy for family } \\
\text { and friends during leisure time? } \\
\text { (reversed) }\end{array}$ & $50.00(20.04)$ & $3.4(1)$ & $13.8(4)$ & $69.0(20)$ & $6.9(2)$ & $6.9(2)$ \\
\hline $\begin{array}{l}\text { 6. Do you feel that every working hour is } \\
\text { tiring for you? }\end{array}$ & $31.03(21.81)$ & $24.1(7)$ & $31.0(9)$ & $41.4(12)$ & $3.4(1)$ & $0(0)$ \\
\hline $\begin{array}{l}\text { 7. Are you exhausted in the morning at the } \\
\text { thought of another day at work? }\end{array}$ & $36.61(24.04)$ & $17.9(5)$ & $28.6(8)$ & $46.4(13)$ & $3.6(1)$ & $3.6(1)$ \\
\hline
\end{tabular}

\section{Results}

\section{Demand}

\section{Corporal punishment}

During the training workshop, participants named corporal punishment, especially beating with a stick, to be a very common and generally accepted way of punishing a child in the school and family setting. Other forms of physical or emotional violence named were pinching, slapping, burning extremities, yelling, insulting, isolating, or withholding meals. They also reported disciplinary measures like warning the child or giving the child extra chores. In the school setting additional penalties, such as push-ups and jumping like a frog, were reported. The participants' attitude towards corporal punishment was generally positive, with most of the participants rating it as a necessity in the education and upbringing of a child, for example, "We wouldn't be able to control the students without corporal punishment" and "I believe Tanzanians can't survive without a stick."

In the sessions about self-reflection, participants reported their own experiences with corporal punishment. Further, 16 of 17 participants (94\%) reported having experienced corporal punishment as a child. For example, "The teacher punished me for my bad handwriting. He beat me with a stick. Since that time I hated the teacher and the subject." or "I got 40 strokes from a teacher. I was so scared that I shit my pants." Other experienced forms of punishment reported were additional tasks (29\%; $n=5$ of 17) and isolation $(18 \% ; n=3$ of 17$)$. The punishment was undertaken by teachers, parents, and other relatives. All of the participants with experiences of corporal punishment reported negative feelings, such as anxiety, fear, shame, guilt, unlovingness, feelings of revenge, and hatred. 
Using corporal punishment as a disciplinary strategy against their students themselves was reported by 14 of 17 participants (82\%), e.g., "When I punish the students, they have to pull down their trousers and I punish them with a stick." Of these, 13 (93\%) reported experiencing negative feelings (e.g., "Sometimes the children make me so angry that I beat them. Afterwards I feel bad.") and 5 (36\%) also reported experiencing positive feelings (e.g. "I feel good punishing the children with a stick, because I am responsible for changing their behavior."). They gave different reasons for using corporal punishment, for example, feeling forced by the group pressure of other teachers to beat a misbehaving child, feeling responsible for changing the child's behavior, being angry, and using it as a time-efficient way of punishing.

\section{Working conditions}

Participants reported working $M=51.79$ hours per week $(S D=8.98$; range $37-84 ; n=29$ ). Out of the time spent working, $81 \%$ was utilized in giving and preparing classes, and $19 \%$ was spent interacting with students $(n=27)$. They rated their current workload on a scale from 0 (very low workload) to 10 (very high workload) with $M=6.76(S D=1.90$; range $5-10 ; n=29)$. On the work-related burnout section of the CBI, 22\% ( $n=6$ of 27 ) showed high burnout symptoms $(M=39.55 ; S D=12.99$; range $14.29-64.29 ; n=27$; see Table 2). The majority of the teachers (68\%; $n=19$ of 27$)$ rated their work as either somewhat or highly emotionally exhausting.

Participants reported the difficulties they face at work in an open-ended question. Forty-seven percent $(n=14$ of 30$)$ named problems in interactions with students, especially with students' misbehavior and with exceptionally demanding students (students with learning difficulties, family problems, or aggressive behavior). Another area of concern named by $67 \%(n=20$ of 30$)$ were the working conditions, in particular, the work overload, the lack of material, the difficulties in the collaboration with the school management, and the high number of students in class.

\section{Implementation}

The trainers evaluated the implementation of each training session $(N=24)$ on a 4-point Likert scale from 0 (poor) to 3 (excellent). Participation was good $(M=1.83 ; S D=.70)$, with most participants engaging actively in the training workshop, e.g., in various discussions and small group activities. Participants were also motivated $(M=1.79 ; S D=.51)$. Time management of the sessions was adequate $(M=1.83 ; S D=.70)$; however, the sessions sometimes ran later because of the participants' strong need to discuss individual cases. The trainers perceived the participants' comprehension as good $(M=1.54 ; S D=.51)$. This finding is supported by the participants 
reporting a very good understanding of the training content directly after the training $(M=3.26, S D=.45$; range $3-4 ; n=23$; scale $0=$ understood nothing to $4=$ understood everything).

\section{Acceptability}

Before the training, participants rated their motivation to participate in the training as very high $(M=8.68 ; S D=2.39$; range $1-10 ; n=28)$ and they expected the training to be helpful in their daily work $(M=9.07 ; S D=1.71$; range $3-10 ; n=29$; scale $0=$ not at all to $10=$ very $m u c h$ ).

After the training, participants' acceptance of the training was measured with questions about their satisfaction regarding ICC-T content $(M=2.63$; $S D=.49 ; N=24)$, teaching methods $(M=2.63 ; S D=.49 ; N=24)$, trainers $(M=2.50 ; S D=.59 ; N=24)$, and the training in general $(M=2.63 ; S D=.58$; $N=24)$ on a 4 -point Likert scale $(0=$ poor to $3=$ excellent $)$, indicating a high acceptance. Concordantly, all participants $(100 \% ; n=24)$ said they would recommend the training to others.

Participants freely stated that the sessions about effective discipline strategies and maltreatment prevention were of high importance to them $(92 \% ; n$ $=22$ of 24$)$. Of these, 73\% $(n=16$ of 22$)$ named non-violent discipline strategies, $50 \%$ ( $n=11$ of 22$)$ reinforcement of the students, and $25 \%(n=6$ of 24) awareness of the consequences of corporal punishment. Teachers wrote, for example, "It is better to pay more attention to the positive behavior of a child and to reward them than to punish the negative behavior" and "I will be more creative and find ways to change a child's misbehavior without hurting him or her." Further, the sessions about teacher-student interaction $(50 \% ; n=12$ of 24$)$ and identifying and supporting burdened students (38\%; $n=9$ of 24$)$ were rated as highly important for the participants as well. Moreover, $92 \%$ ( $n=22$ of 24$)$ reported a better understanding of the students as a result of the training (e.g., "A child is another me, only younger. That means: What I don't want done to me should not be done to a child either," "I learned that it is not punishment but showing concern that leads to changes in weak students").

\section{Integration into daily life}

Participants reported high use of ICC-T aspects in their daily work $(M=2.70 ; S D$ $=.76$; range $1-4 ; n=23$; scale $0=$ no aspects to $4=$ all aspects) 3 months after the training. The majority (74\%; $n=17$ of 23 ) reported in an open-ended question that they used the discipline strategies learned in the training. Of these, the most cited were strategies to maintain good behavior (57\%; $n=13$ of 23$)$ and strategies to change misbehavior $(52 \% ; n=12$ of 23$)$. The use of other strategies to improve the teacher-student interaction was named by $39 \%(n=9$ of 23$)$. 
Table 3. Summary of the Main Results.

\begin{tabular}{ll}
\hline Categories & \\
\hline Demand & Results \\
Working conditions & - High work load \\
& - High work-related burnout symptoms \\
Corporal & - Gifficulties in the teacher-student interaction and working conditions \\
punishment & - High rate of experiencing corporal punishment as a child, connected with \\
& - Hegative feelings \\
Implementation & - Good participation, motivation, time management, and comprehension of \\
& - He training \\
Acceptability & - High motivation to participate \\
Integration in daily life & - Frequent use of the training aspects in the teachers daily work \\
Limited effectiveness & - Improvements in the teacher-student relationship \\
& - Improvements in the students' behavior
\end{tabular}

\section{Limited effectiveness}

Three months after the training, $83 \%(n=19$ of 23$)$ of the participants reported changes in their work due to the training. Concerning the relationship to the students, $96 \%(n=22$ of 23$)$ reported improvements and $4 \%(n=$ 1 of 23) reported no change as a result of the training. Teachers named changes, such as "The students tell me so many things" and "They feel like I am their friend." Further, 96\% $(n=22$ of 23$)$ reported better behavior and $4 \%$ ( $n=1$ of 23 ) reported no change in the behavior of the students resulting from changes in their own behavior, for example, "The students are behaving well without me using corporal punishment" and "The students listen to me." A summary of the main study results can be found in Table 3.

\section{Discussion}

There is a high prevalence of school corporal punishment in many countries worldwide (Gershoff, 2017; GIEACPC, 2016b) and a lack of scientifically evaluated interventions addressing this issue. This pilot feasibility study explored strategies to resolve these problems by evaluating the intervention approach ICC-T. ICC-T is a comprehensive training workshop for teachers aiming at preventing corporal punishment and at improving the teacherstudent relationship in school settings. It showed a promising feasibility in the examined teacher sample in a primary school in Tanzania.

In accordance with previous research in Tanzania and other SSA countries (Devries et al., 2014; Feinstein \& Mwahombela, 2010; GIEACPC, 2016b; Hecker et al., 2014), participants reported high use of corporal punishment 
in school. They regarded corporal punishment as a necessity in the education of children, mirroring a widely held belief in Tanzanian society (Tanzania Daily News, 2013). The poor working conditions, considerable work-related stress, and problems in teacher-student interaction were also comparable with previous research (Barrett, 2005; Bennell \& Akyeampong, 2007; Vavrus \& Bartlett, 2012).

The widespread use of corporal punishment, together with the problems in the teacher-student interaction in our sample, clearly indicated the necessity for intervention. However, research on interventions preventing school corporal punishment is scarce. To our knowledge there are only a few other studies addressing violence prevention in schools through teacher training (Devries et al., 2015; Gershoff, 2017). ICC-T extends the range of interventions in offering prevention training by delivering important educational competencies and initializing change in teachers' attitudes. It further offers an approach that is applicable in settings with low resources. In Tanzania, a violence prevention training for teachers is all the more important, since teachers' regular training does not equip them with adequate skills regarding non-violent discipline (Nkuba \& Kyaruzi, 2015).

Despite challenging conditions and little resources in the school, ICC-T showed a good feasibility. Implementation of the training workshop was successful, with a good understanding of the content and participants engaging actively in the training workshop. Further, participants showed a high acceptability before and after the training workshop. They reported a frequent use of the training aspects in their daily work life, as well as substantial improvements in the teacher-student relationships, and more desired behavior from the students. This is in line with the findings for the ICC version for caregivers in institutional care (Hermenau et al., 2015). Consistent with earlier studies (Feinstein \& Mwahombela, 2010; Yaghambe \& Tshabangu, 2013), the participating teachers reported corporal punishment to be a very common, effective, and socially accepted way of educating a child in Tanzania. Accordingly, we expected skepticism and resistance from the participants towards the training content. However, the participative approach and focus on creating a trusting atmosphere may have helped to overcome skepticism and to reduce resistance. Further, the teachers' reflection on their own experiences of corporal punishment and their current way of punishing the children themselves, may have contributed to them reconsidering common beliefs. For example, the trainers observed that participants started questioning their own behavior and its effect on the children after the self-reflection units. Accordingly, the study supports the notion that it is possible to broach the issue of corporal punishment with teachers, to discuss negative consequences of this practice, and to question the common attitudes and beliefs on discipline in Tanzania. Yet, so far we cannot infer a change in behavior from the teachers' self-reported attitude change. 
We believe that the preventive intervention ICC-T could also be applicable in other settings. This is because the participants showed many characteristics common to teachers in other studies in SSA countries, and because the ICC-T was feasible despite challenging conditions. However, this hypothesis needs to be tested in further studies.

In sum, the study results indicate the feasibility of ICC-T as well as the teachers' willingness to actively partake in the changing process. Following the United Nation's Sustainable Development Goal Nr. 16.2 (United Nations, 2015), ICC-T aims at preventing school corporal punishment, thereby addressing the public health challenge related to the high prevalence rates of corporal punishment. Subsequent research should focus on assessing the efficacy of ICC-T using rigorous study designs, additionally including students' reports, and assessing long-term efficacy. Addressing this need for further research, we are currently conducting a randomized cluster trial with ICC-T in Tanzania.

The present study has some limitations. Although the teachers in our sample share common characteristics with teachers in SSA and elsewhere, the small sample size limits our capacity to generalize to other settings and countries with certainty. Due to the uncontrolled study design, no causal conclusions can be drawn. This study did not systematically assess changes in teachers' corporal punishment before and after the training; thus, teachers' reported improvements have to be interpreted with caution and conclusions about the effectiveness of the intervention are preliminary. The reported attitude changes do not necessarily imply changes in the teachers' actual disciplinary behavior. Further, a potential bias of social desirability in the teachers' self-reports cannot be completely ruled out.

\section{Conclusion}

The prevention of corporal punishment in schools has so far been insufficiently addressed in research and practice, although the need for preventive measures is high. ICC-T intervention addresses the issue of corporal punishment in school in order to initialize a change in attitude and behavior of teachers. Our study provides the first promising results in the feasibility and integration in the teachers' daily work. The training's efficacy, sustainability, and effects on the well-being of students are currently being studied in a follow-up cluster randomized trial with ICC-T in Tanzania.

\section{Acknowledgments}

This research was supported by Misereor and vivo international. The authors wish to thank all teachers who participated in this study. Further, the authors gratefully acknowledge the highly motivated research team: Astrid Pabst, Getrude Mkinga, Andrew Mtitu, and Leila 
Samson; and James Moran who critically reviewed the manuscript. Elisa Kaltenbach and Katharin Hermenau contributed equally to this work.

\section{ORCID}

Tobias Hecker (D) http://orcid.org/0000-0001-9272-0512

\section{References}

American Academy of Pediatrics. (1999). Caring for your school-age child: Ages 5 to 12 (Revised). E. L. Schor (Ed.), New York, NY: Bantam Books.

Anbarasan, E. (1999). Spare the rod, save the child. In J. Kohut (Ed.), Memory: Making peace with a violent past (pp. 14-16). Paris, France: United Nations Educational Scientific and Cultural Organization, the Courier.

Antonowicz, L. (2010). Too often in silence: A report on school-based violence in West and Central Africa. UNICEF, Plan West Africa, Save the Children Sweden West Africa and ActionAid. Retrieved from https://www.unicef.org/wcaro/documents_publications_4271.html

Barrett, A. M. (2005). Teacher accountability in context: Tanzanian primary school teachers' perceptions of local community and education administration. Compare: A Journal of Comparative and International Education, 35(1), 43-61. doi:10.1080/03057920500033530

Benbenishty, R., Zeira, A., \& Astor, R. A. (2002). Children's reports of emotional, physical and sexual maltreatment by educational staff in Israel. Child Abuse and Neglect, 26(8), 763782. doi:10.1016/S0145-2134(02)00350-2

Bennell, P., \& Akyeampong, K. (2007). Teacher motivation in Sub-Saharan Africa and South Asia. London, UK: Department for International Development. Retrieved from http://r4d. dfid.gov.uk/PDF/Outputs/PolicyStrategy/ResearchingtheIssuesNo71.pdf

Boden, J. M., Horwood, L. J., \& Fergusson, D. M. (2007). Exposure to childhood sexual and physical abuse and subsequent educational achievement outcomes. Child Abuse and Neglect, 31(10), 1101-1114. doi:10.1016/j.chiabu.2007.03.022

Bonell, C., Jamal, F., Harden, A., Wells, H., Parry, W., Fletcher, A., ... Moore, L. (2013). Systematic review of the effects of schools and school environment interventions on health: Evidence mapping and synthesis. Public Health Research, 1(1), 1-8. doi:10.3310/phr01010

Borritz, M., Rugulies, R., Christensen, K. B., Villadsen, E., \& Kristensen, T. S. (2006). Burnout as a predictor of self-reported sickness absence among human service workers: Prospective findings from three year follow up of the PUMA study. Occupational and Environmental Medicine, 63(2), 98-106. doi:10.1136/oem.2004.019364

Bowen, D. J., Kreuter, M., Spring, B., Linnan, L., Weiner, D., Bakken, S., ... Fernandez, M. (2009). How we design feasibility studies. American Journal of Preventative Medicine, 36 (5), 452-457. doi:10.1016/j.amepre.2009.02.002

Burton, P. (2005). Suffering at school: Results of the Malawi gender-based violence in schools survey. Pretoria, South Africa: Institute for Security Studies. Retrieved from https://www. issafrica.org/pubs/Books/SufferingAtSchoolOct05/SufferingAtSchool.pdf

Devries, K. M., Child, J. C., Allen, E., Walakira, E., Parkes, J., \& Naker, D. (2014). School violence, mental health, and educational performance in Uganda. Pediatrics, 133(1), e129e137. doi:10.1542/peds.2013-2007

Devries, K. M., Knight, L., Child, J. C., Mirembe, A., Nakuti, J., Jones, R., ... Naker, D. (2015). The Good School Toolkit for reducing physical violence from school staff to primary 
school students: A cluster-randomised controlled trial in Uganda. The Lancet Global Health, 3(7), e378-e386. doi:10.1016/S2214-109X(15)00060-1

Feinstein, S., \& Mwahombela, L. (2010). Corporal punishment in Tanzania's schools. International Review of Education, 56(4), 399-410. doi:10.1007/s11159-010-9169-5

Flannery, D. J., Vazsonyi, A. T., Liau, A. K., Guo, S., Powell, K. E., Atha, H., ... Embry, D. (2003). Initial behavior outcomes for the peacebuilders universal school-based violence prevention program. Developmental Psychology, 39(2), 292-308. doi:10.1037/00121649.39.2.292

Flook, L., Goldberg, S. B., Pinger, L., Bonus, K., \& Davidson, R. J. (2013). Mindfulness for teachers: A pilot study to assess effects on stress, burnout and teaching efficacy. Mind, Brain, and Education, 7(3), 182-195. doi:10.1111/mbe.12026

Frankenberg, S. J., Holmqvist, R., \& Rubenson, B. (2010). The care of corporal punishment: Conceptions of early childhood discipline strategies among parents and grandparents in a poor and urban area in Tanzania. Childhood: A Global Journal of Child Research, 17(4), 455-469. doi:10.1177/0907568209349314

Gershoff, E. T. (2002). Corporal punishment by parents and associated child behaviors and experiences: A meta-analytic and theoretical review. Psychological Bulletin, 128(4), 539579. doi:10.1037/0033-2909.128.4.539

Gershoff, E. T. (2017). School corporal punishment in global perspective: Prevalence, outcomes, and efforts at intervention. Psychology, Health \& Medicine, 22(S1), 224-239. doi:10.1080/13548506.2016.1271955

Gershoff, E. T., \& Grogan-Kaylor, A. (2016). Spanking and child outcomes: Old controversies and new meta-analyses. Journal of Family Psychology, 30(4), 453-469. doi:10.1037/ fam0000191

Global Advocacy Team. (2012). The campaign to stop violence in schools: Third progress report. Woking, UK. Retrieved from https://plan-international.org/publications/learn-with out-fear-third-progress-report

Global Initiative to End All Corporal Punishment of Children [GIEACPC]. (2012). Resources for eliminating corporal punishment in schools. Retrieved from www.endcorporalpunish ment.org/assets/pdfs/reports-thematic/Schools-resources-2012.pdf

Global Initiative to End All Corporal Punishment of Children [GIEACPC]. (2015a). Ending legalised violence against children. Retrieved from www.endcorporalpunishment.org/assets/ pdfs/reports-global/Global-report-2015.pdf

Global Initiative to End All Corporal Punishment of Children [GIEACPC]. (2015b). Prohibiting all corporal punishment of children: Progress and delay. Retrieved from endcorporalpunishment.org/assets/pdfs/reports-global/Progress-delay-2015-10.pdf

Global Initiative to End All Corporal Punishment of Children [GIEACPC]. (2016a). Corporal punishment of children: Review of research on its impact and associations. Retrieved from www.endcorporalpunishment.org/assets/pdfs/research-summaries/Review-researcheffects-corporal-punishment-June-2016.pdf

Global Initiative to End All Corporal Punishment of Children [GIEACPC]. (2016b). Corporal punishment of children: Summaries of prevalence and attitudinal research in the last 10 years. Retrieved from www.endcorporalpunishment.org/assets/pdfs/research-summaries/ Global research summaries.pdf

Global Initiative to End All Corporal Punishment of Children [GIEACPC]. (2016c). Corporal punishment of children in the United Republic of Tanzania. Retrieved from www.endcor poralpunishment.org/assets/pdfs/states-reports/URTanzania.pdf

Global Initiative to End All Corporal Punishment of Children [GIEACPC]. (2016d). Global progress towards prohibiting all corporal punishment. Retrieved from endcorporalpunish ment.org/assets/pdfs/legality-tables/Global progress table with terrs \%28alphabetical\%29.pdf 
Greydanus, D. E., Pratt, H. D., Spates, C. R., Blake-Dreher, A. E., Greydanus-Gearhart, M. A., \& Patel, D. R. (2003). Corporal punishment in schools: Position paper of the society for adolescent medicine. Journal of Adolescent Health, 32(5), 385-393. doi:10.1016/S1054-139X (03)00042-9

Hecker, T., Hermenau, K., Isele, D., \& Elbert, T. (2014). Corporal punishment and children's externalizing problems: A cross-sectional study of Tanzanian primary school aged children. Child Abuse \& Neglect, 38(5), 884-892. doi:10.1016/j.chiabu.2013.11.007

Hecker, T., Hermenau, K., Salmen, C., Teicher, M., \& Elbert, T. (2016). Harsh discipline relates to internalizing problems and cognitive functioning: Findings from a cross-sectional study with school children in Tanzania. BMC Psychiatry, 16(1), 118. doi:10.1186/s12888016-0828-3

Hermenau, K., Kaltenbach, E., Mkinga, G., \& Hecker, T. (2015). Improving care quality and preventing maltreatment in institutional care-A feasibility study with caregivers. Frontiers in Psychology, 6, 937. doi:10.3389/fpsyg.2015.00937

Hyland, M. E., Alkhalaf, A. M., \& Whalley, B. (2013). Beating and insulting children as a risk for adult cancer, cardiac disease and asthma. Journal of Behavioral Medicine, 36(6), 632640. doi:10.1007/s10865-012-9457-6

Khoury-Kassabri, M. (2006). Student victimization by educational staff in Israel. Child Abuse and Neglect, 30(6), 691-707. doi:10.1016/j.chiabu.2005.12.003

Kristensen, T. S., Borritz, M., Villadsen, E., \& Christensen, K. B. (2005). The copenhagen burnout inventory: A new tool for the assessment of burnout. Work \& Stress, 19(3), 192207. doi:10.1080/02678370500297720

Krug, E.G., Dahlberg, L. L., Mercy, J. A., Zwi, A. B. \& Lozano, R. (2002). World report on violence and health. Geneva, Switzerland: World Health Organization.

Leech, N. L., \& Onwuegbuzie, A. J. (2007). An array of qualitative data analysis tools: A call for data analysis triangulation. School Psychology Quarterly, 22(4), 557-584. doi:10.1037/ 1045-3830.22.4.557

McCabe, K. M., Lucchini, S. E., Hough, R. L., Yeh, M., \& Hazen, A. (2005). The relation between violence exposure and conduct problems among adolescents: A prospective study. American Journal of Orthopsychiatry, 75(4), 575-584. doi:10.1037/0002-9432.75.4.575

Milfont, T. L., Denny, S., Ameratunga, S., Robinson, E., \& Merry, S. (2008). Burnout and wellbeing: Testing the Copenhagen Burnout Inventory in New Zealand teachers. Social Indicators Research, 89, 169-177. doi:10.1007/s11205-007-9229-9

Mweru, M. (2010). Why are Kenyan teachers still using corporal punishment eight years after a ban on corporal punishment? Child Abuse Review, 19(4), 248-258. doi:10.1002/ car. 1121

Naker, D. (2005). Violence against children: The voices of Ugandan children and adults. Kampala, Uganda: Raising Voices and Save the Children in Uganda. Retrieved from http://raisingvoices.org/wp-content/uploads/2013/03/downloads/resources/violence_ against_children.pdf

Nkuba, M., \& Kyaruzi, E. (2015). Is it not now? School counselors' training in Tanzania secondary schools. Journal of Education and Practice, 6(19), 160-170.

Nolan, J. D., Filter, K. J., \& Houlihan, D. (2014). Preliminary report: An application of the Good Behavior Game in the developing nation of Belize. School Psychology International, 35(4), 421-428. doi:10.1177/0143034313498958

Norman, R. E., Byambaa, M., De, R., Butchart, A., Scott, J., \& Vos, T. (2012). The long-term health consequences of child physical abuse, emotional abuse, and neglect: A systematic review and meta-analysis. PLoS Medicine, 9(11), 1-31. doi:10.1371/journal.pmed.1001349 
Parkes, J., \& Heslop, J. (2013). Stop violence against girls in school: A cross-country analysis of change in Ghana, Kenya and Mozambique. ActionAid International. Retrieved from http:// www.actionaid.org/sites/files/actionaid/svags_review_final.pdf

Pereznieto, P., Harper, C., Clench, B., \& Coarasa, J. (2010). The economic impact of school violence: A report for Plan International. London, UK: Plan International \& Overseas Development Institute. Retrieved from https://www.odi.org/sites/odi.org.uk/files/odiassets/publications-opinion-files/6289.pdf

Portela, M. J. O., \& Pells, K. (2015). Corporal punishment in schools: Longitudinal evidence from Ethiopia, India, Peru and Viet Nam. Florence, Italy: UNICEF Office of Research. Retrieved from https://www.unicef-irc.org/publications/pdf/CORPORAL PUNISHMENTfinal.pdf

Research and Analysis Working Group United Republic of Tanzania. (2007). Tanzanian children's perceptions of education and their role in society: Views of the children 2007. Dar es Salaam, Tanzania: Policy Research for Development (REPOA). Retrieved from http:// www.repoa.or.tz/documents_storage/Research and Analysis/Views_of_the_Children_2007. pdf

Schiff, M., \& BarGil, B. (2004). Children with behavior problems: Improving elementary school teachers' skills to keep these children in class. Children and Youth Services Review, 26(2), 207-234. doi:10.1016/j.childyouth.2004.01.009

Schussler, D. L., Jennings, P. A., Sharp, J. E., \& Frank, J. L. (2016). Improving teacher awareness and well-being through CARE: A qualitative analysis of the underlying mechanisms. Mindfulness, 7(1), 130-142. doi:10.1007/s12671-015-0422-7

Tanzania Daily News. (2013). Public schools to continue using corporal punishment. Retrieved from http://allafrica.com/stories/

Taylor, C., Harrison, J., Haimovitz, K., Oberle, E., Thomson, K., Schonert-Reichl, K., \& Roeser, R. W. (2016). Examining ways that a mindfulness-based intervention reduces stress in public school teachers: A mixed-methods study. Mindfulness, 7(1), 115-129. doi:10.1007/s12671-015-0425-4

Tomoda, A., Suzuki, H., Rabi, K., Sheu, Y., Polcari, A., \& Teicher, M. H. (2009). Reduced prefrontal cortical gray matter volume in young adults exposed to harsh corporal punishment. Neuroimage, 47(Suppl 2), T66-T71. doi:10.1016/j.neuroimage.2009.03.005

United Nations. (2015). Transforming our world: The 2030 agenda for sustainable development. Retrieved from https://sustainabledevelopment.un.org/content/documents/21252030 Agenda for Sustainable Development web.pdf

United Nations Children's Fund. (2014). Hidden in plain sight: A statistical analysis of violence against children. New York, NY: UNICEF. Retrieved from http://files.unicef.org/ publications/files/Hidden_in_plain_sight_statistical_analysis_EN_3_Sept_2014.pdf

Vavrus, F., \& Bartlett, L. (2012). Comparative pedagogies and epistemological diversity: Social and materials contexts of teaching in Tanzania. Comparative Education Review, 56(4), 634658. doi:10.1086/667395

Yaghambe, R. S., \& Tshabangu, I. (2013). Disciplinary networks in secondary schools: Policy dimensions and children's rights in Tanzania. Journal of Studies in Education, 3(4), 42-56. doi:10.5296/jse.v3i4.4167 